\title{
Head Blight Gradients Caused by Gibberella zeae from Area Sources of Inoculum in Wheat Field Plots
}

\author{
W. G. D. Fernando, T. C. Paulitz, W. L. Seaman, P. Dutilleul, and J. D. Miller
}

First, third, and fifth authors: Agriculture and Agri-Food Canada, Eastern Cereal Oilseed Research Centre, Ottawa, Ontario K1A 0C6, Canada; and second and fourth authors: Macdonald Campus of McGill University, Department of Plant Science, Ste. Anne de Bellevue, Quebec H9X 3V9, Canada.

Accepted for publication 16 January 1997

\begin{abstract}
Fernando, W. G. D., Paulitz, T. C., Seaman, W. L., Dutilleul, P., and Miller, J. D. 1997. Head blight gradients caused by Gibberella zeae from area sources of inoculum in wheat field plots. Phytopathology 87:414-421.

The spread of Fusarium head blight of wheat from a small area inoculum source was examined in wheat plots $\left(100,625\right.$, or $\left.2,500 \mathrm{~m}^{2}\right)$ inoculated in the center with Gibberella zeae-colonized corn kernels or macroconidia sprayed on heads at anthesis. With the first inoculation method, disease foci were produced from ascospores released from perithecia formed on inoculated kernels. With the second inoculation method, disease foci were produced by macroconidia directly applied to the heads. Some plots were misted during anthesis. Plots were divided into grids, and disease incidence on spikelets and seeds was assessed at the grid intersections. Isopath contour maps were constructed using an interpolation procedure based on a weighted least squares method. Disease gradients were constructed from the isopath contours in the direction parallel to average nightly wind vectors using an exponential model. This study was conducted over a 3-year period at two sites: one in Quebec and one

in Ontario. Both inoculation methods resulted in a discrete, primary focus of head blight in each plot, with one or two smaller secondary foci in some plots. The highest incidence of disease on spikelets or seed was commonly displaced somewhat from the inoculum source, usually downwind. The gradient slopes of seed and spikelet infection ranged from -0.10 to $-0.43 \mathrm{~m}^{-1}$ in plots with ascospore inoculum and from -0.48 to $-0.79 \mathrm{~m}^{-1}$ in plots inoculated with macroconidia. Seed infection declined to $10 \%$ of the maximum within 5 to $22 \mathrm{~m}$ from the focal center in ascospore-inoculated plots, and within $5 \mathrm{~m}$ in a macroconidia-inoculated plot. Gradients were usually steeper upwind compared with downwind of the inoculum source. In misted plots, incidence of disease was higher and more diffuse than in nonirrigated plots. Based on gradients and dispersal patterns, disease foci in plots inoculated with G. zeae-colonized corn kernels probably arose from airborne ascospores rather than from splashborne macroconidia and were the result of infection events that occurred over a short period of time. Comparison of conidial- and ascosporederived disease gradients indicated a lack of secondary infection, confirming that Fusarium head blight is primarily a monocyclic disease.
\end{abstract}

Fusarium graminearum Schwabe group 2 (teleomorph $=G i b$ berella zeae (Schwein.) Petch) causes head blight (scab) of wheat and pink ear rot of corn in eastern parts of Canada and the United States. Group 2 isolates produce perithecia in nature, while group 1 isolates, which cause crown rots in semiarid areas, do not. $G$. zeae produces deoxynivalenol and zearalenone in the kernels of corn and wheat (21), and accumulation of these mycotoxins in the grain increases the importance of this pathogen to agriculture (32). In wheat, head blight can greatly reduce grain yield and quality $(4,8)$. Moreover, when contaminated grain is consumed, the mycotoxins produced by the fungus can cause feeding refusal and reproductive disorders in cattle, swine, and poultry.

In eastern Canada, head blight and ear rot epidemics occur sporadically at intervals of several years (32). In 1993 and 1994, several epidemics of head blight occurred in the wheat-growing areas of north central United States and the Red River Valley of Manitoba. Losses exceeding \$1 billion were estimated for 1993 in the United States, and 2.4 and 1.2 million metric tons were lost in North Dakota in 1993 and 1994, respectively (28).

G. zeae overwinters on corn stalks and wheat straw and produces perithecia and sporodochia that give rise to ascospores and macroconidia, respectively. The fungus also may survive on weeds and natural vegetation (15). In eastern Canada, perithecia form in late spring or early summer. Ascospores are ejected from perithecia and deposited on wheat heads at the time of flowering

Corresponding author: T. C. Paulitz; E-mail address: paulitz@nrs.mcgill.ca

Publication no. P-1997-0304-01R

(C) 1997 Department of Agriculture and Agri-Food, Government of Canada
(2). Blight symptoms are formed on the rachis and individual spikelets. Under warm, wet conditions, mycelium and sporodochia often form on the blighted spikelets, but the importance of these conidia in secondary infection of other heads is not known. Currently, the only practiced control for head blight is crop rotation with nonhosts, such as soybeans, and avoidance of highly susceptible cultivars of spring wheat, such as Roblin and Max and all durum wheats. No adapted cultivars are completely resistant to the disease, and tests of protectant fungicides usually do not result in acceptable disease suppression (25).

Although the life cycle of the pathogen is well understood $(25,32)$, little is known about the epidemiology of the sexual stage. This information may be useful for the development of management strategies. Relevant questions include how far can ascospores travel from an inoculum source, what is the effect of wind direction on spread of inoculum, can gradients of disease be measured from an inoculum source, does secondary infection occur (is the disease polycyclic), and are airborne ascospores more important than splash-dispersed macroconidia? The objective of this study was to address these questions using small area sources of G. zeae inoculum in field plots of wheat. Preliminary reports have been published $(11,27)$.

\section{MATERIALS AND METHODS}

Inoculum preparation. G. zeae isolate DAOM 178148 from the culture collection of Biosystematics Research Centre, Ottawa, Ontario, Canada, was grown on synthetic nutrient agar (SNA) (24) for 10 days. To produce macroconidia, a fresh tomato medium was prepared with $100 \mathrm{~g} /$ liter of fresh ripe tomatoes, cut into $2-\mathrm{cm}$ 
pieces, and soaked for $2 \mathrm{~h}$ in distilled water. The water-tomato mixture was filtered through cheesecloth, $\mathrm{NaCl}$ was added (16 $\mathrm{g} /$ liter), and the filtrate was autoclaved. Plugs of mycelium (0.5 $\mathrm{cm}$ in diameter) were then placed in the tomato medium in 1-liter flasks under aeration (bubbling with filtered air) and near UV light for 7 days or until macroconidia had formed. Twenty milliliters of a conidial suspension $\left(5 \times 10^{4} / \mathrm{ml}\right)$ were transferred into 1-liter canning jars containing $500 \mathrm{~g}$ of previously autoclaved corn kernels. The jars were sealed with a metal lid that had two holes (6 $\mathrm{mm}$ in diameter) for air exchange. A 70-mm-diameter filter disk (Fungi Perfecti, Olympia, WA) was placed on the inside of the lid to prevent passage of contaminants through the air exchange holes. Jars were shaken lightly every day to break up clumps of kernels and mycelia and were incubated at $20^{\circ} \mathrm{C}$ under $16-\mathrm{h} /$ day fluorescent lighting for 6 weeks.

Ste. Anne, 1992 and 1993. The susceptible red spring wheat (Triticum aestivum L.) 'Max' was planted in a $10 \times 10-\mathrm{m}$ plot at the Horticulture Farm of the Macdonald Campus of McGill University in early May, 1992 and 1993. Rows were planted $10 \mathrm{~cm}$ apart with approximately 50 plants/m of row. During the last week of May, 10 liters of inoculated corn kernels were spread in a $4 \times$ 4-m area in the center of the plot. Ascospores were trapped $1 \mathrm{~m}$ away from the plot in a downwind direction $\left(\mathrm{N} 20^{\circ} \mathrm{E}\right.$ from the center of the plot) with a Burkard 7-day spore sampler (Burkard Scientific Sales, Ltd., Rickmansworth, United Kingdom). Temperature and relative humidity were measured electronically with a sensor (model HMP35A; Vaisala, Helsinki, Finland), and leaf wetness was monitored with a sensor (model 237; Campbell Scientific Inc., Logan, UT). Data were stored on a CR-10 data logger (Campbell Scientific Inc.). Wind velocity, wind direction, and rainfall were measured at a station approximately $1 \mathrm{~km}$ from the site.

To assess disease and seed infection, plots were subdivided according to a $5 \times 5$ grid with a spacing of $2 \mathrm{~m}$ and wheat heads were harvested from $0.25-\mathrm{m}^{2}$ subplots centered at the grid nodes. For disease assessment, heads were sampled when healthy spikelets were still green but infected spikelets had turned brown. This occurred about 3 weeks after anthesis, during the first week of August. To measure incidence of disease on spikelets, all the heads from each subplot were pooled, 50 heads were randomly selected from each subplot, and the total numbers of spikelets and infected spikelets were counted on each head. Incidence was expressed as average percentage of spikelets with symptoms per head. In 1993, incidence of G. zeae in seed was assessed in heads harvested at maturity from each subplot. Five 10-seed subsamples of hand-threshed seeds from each subplot sample were surfacedisinfested for $6 \mathrm{~min}$ in $0.5 \%$ sodium hypochlorite, rinsed for 15 min in water, blotted dry, and placed on a Fusarium-selective medium (10). G. zeae isolate 178148 produced characteristic yellow colonies on this medium.

Ottawa, 1993. Three adjacent side-by-side $10 \times 10-\mathrm{m}$ plots of cultivar Max were established at the Central Experimental Farm, Agriculture and Agri-Food Canada, Ottawa, Ontario, Canada. Rows were $18 \mathrm{~cm}$ apart, with a planting density of approximately 450 plants $/ \mathrm{m}^{2}$. The center $1 \times 1-\mathrm{m}$ area of the first plot was inoculated with 2 liters of colonized corn kernels on 21 June at the preboot stage in 1993. No inoculum was placed in the second plot. In the third plot, heads of wheat in the center $1 \times 1 \mathrm{~m}$ were sprayed with macroconidia of $F$. graminearum $\left(5 \times 10^{5}\right.$ spores $\left./ \mathrm{ml}\right)$ at anthesis (20 and 29 June 1993). Wind direction and velocity were recorded at a site $0.5 \mathrm{~km}$ away. All plots were misted following inoculation for $5 \mathrm{~s}$ every $30 \mathrm{~min}$, from 0600 to $1800 \mathrm{~h}$ until anthesis was complete.

To assess disease and seed infection, wheat plots were subdivided according to a $6 \times 6$ grid with a spacing of $1.67 \mathrm{~m}$ and samples were taken at each grid node $\left(0.25 \mathrm{~m}^{2}\right)$. Disease incidence on spikelets was measured 3 weeks after anthesis, and mature heads were harvested in early September. Heads were frozen at $-20^{\circ} \mathrm{C}$ for later analysis of seed infection.
Ottawa, 1994. The experiments were planted at two locations on the Central Experiment Farm of Agriculture Canada, approximately $1 \mathrm{~km}$ apart. The first site had one $50 \times 50-\mathrm{m}$ plot, and the second site had two main $50 \times 50-\mathrm{m}$ plots and one $10 \times 10-\mathrm{m}$ plot. At the second site, one of the $50 \times 50-\mathrm{m}$ plots was subdivided into four $25 \times 25-\mathrm{m}$ plots, each of which were inoculated. All plots were planted with wheat cultivar Roblin. Rows were $18 \mathrm{~cm}$ apart, with a planting density of approximately 450 plants $/ \mathrm{m}^{2}$. In the 10 $\times 10-\mathrm{m}$ plot, wheat heads at anthesis in the center $1 \times 1-\mathrm{m}$ area were sprayed to runoff with macroconidia of $F$. graminearum (DAOM isolate 178148) at a concentration of $1 \times 10^{6}$ spores per milliliter. In the other plots, 2 liters of colonized corn inoculum was scattered on the soil in the center $1 \times 1-\mathrm{m}$ area of the plots. The corn-based inoculum was placed in the field on 14 June 1994, when plants were at preboot stage. At each experimental site, two Burkard high through-put jet spore traps (Burkard Manufacturing Co., Ltd., Rickmansworth, United Kingdom) sampled viable ascospores and deposited them onto $100 \times 15$-mm petri plates containing Fusarium-selective medium (23). The spore traps were placed in the $50 \times 50-\mathrm{m}$ plots 1.5 and $5.0 \mathrm{~m}$ (site 1 ), and 5 and 10 $\mathrm{m}$ (site 2), downwind from the edge of the corn-based inoculum. The intake chimney of the traps was just above the level of the heads, about $80 \mathrm{~cm}$. Wind direction and velocity were measured at the Central Experimental Farm meteorological station, $1 \mathrm{~km}$ from the plots. Spores were deposited for 2 min once every $30 \mathrm{~min}$ (flow rate of 10 liters/min), and plates were collected at 0800 , 1200, 1600, and 2000 h each day from 6 July until 27 July 1994. Plates were incubated at $26^{\circ} \mathrm{C}$ for 4 to 6 days, and Fusarium colonies were counted. Selected colonies of each type were transferred to plates of SNA with $4.25-\mathrm{cm}^{2}$ pieces of filter paper in the center (24). After 3 to 5 days of incubation, the colonies were identified to species.

To assess seed infection, the $50 \times 50$-m plots were subdivided according to a $10 \times 10$ grid, with $5-\mathrm{m}$ spacing. The $25 \times 25-\mathrm{m}$ plots were subdivided according to a $7 \times 7$ grid, with a spacing of $3.57 \mathrm{~m}$. The $10 \times 10-\mathrm{m}$ plot inoculated with macroconidia was subdivided according to a $6 \times 6$ grid, with a spacing of $1.67 \mathrm{~m}$. At maturity, wheat heads were harvested at the grid nodes, in a $0.125-\mathrm{m}^{2}$ area using a two-row binder (Suzue BX602; Suzue Agricultural Machinery Co., Japan). Heads were threshed using a plot combine thresher (Hege 125 plot combine; H. U. Hege Co., Waldenburg, Germany). Seed infection was assessed as described previously. Disease incidence on spikelets was not assessed at Ottawa in 1994.

Data analysis. Each sample site was assigned $\mathrm{X}$ and $\mathrm{Y}$ geographic coordinates in meters based on its position in the field. Disease incidence on spikelets or seed infection incidence data were used for the $\mathrm{Z}$ axis in mapping. Data were mapped using the MacGridzo version 3 program for the Macintosh computer (Rockware, Inc., Wheatridge, $\mathrm{CO}$ ). A contour map was fitted to the data with an interpolation technique based on weighted least squares. With this technique, the contours equal the observed data at the grid nodes. Contours were interpolated with the four adjacent data points in the grid (rook position) and the four closest points on the diagonal (bishop position), but the points on the diagonal were given less weight (0.71) proportionally to their distance from the center. When the maps were constructed, disease gradients were calculated using the map contours of the disease or infection foci. Two gradients were computed, both parallel to the direction of the average nightly wind vectors for the first 3 weeks of July at that site. One gradient was on the upwind side of the focal center and the other was on the downwind side of the focal center. Data were fitted to the exponential model of Kiyosawa and Shiyomi (18), $y=c e^{-d x}$, in which $y$ equals incidence of seed infection or incidence of spikelet infection, $c$ equals the maximum infection or disease at the center of the focus $x=0, e$ equals the base of natural logarithms, $d$ equals the steepness or slope of the gradient, and $x$ equals the distance from the focal center in meters. 

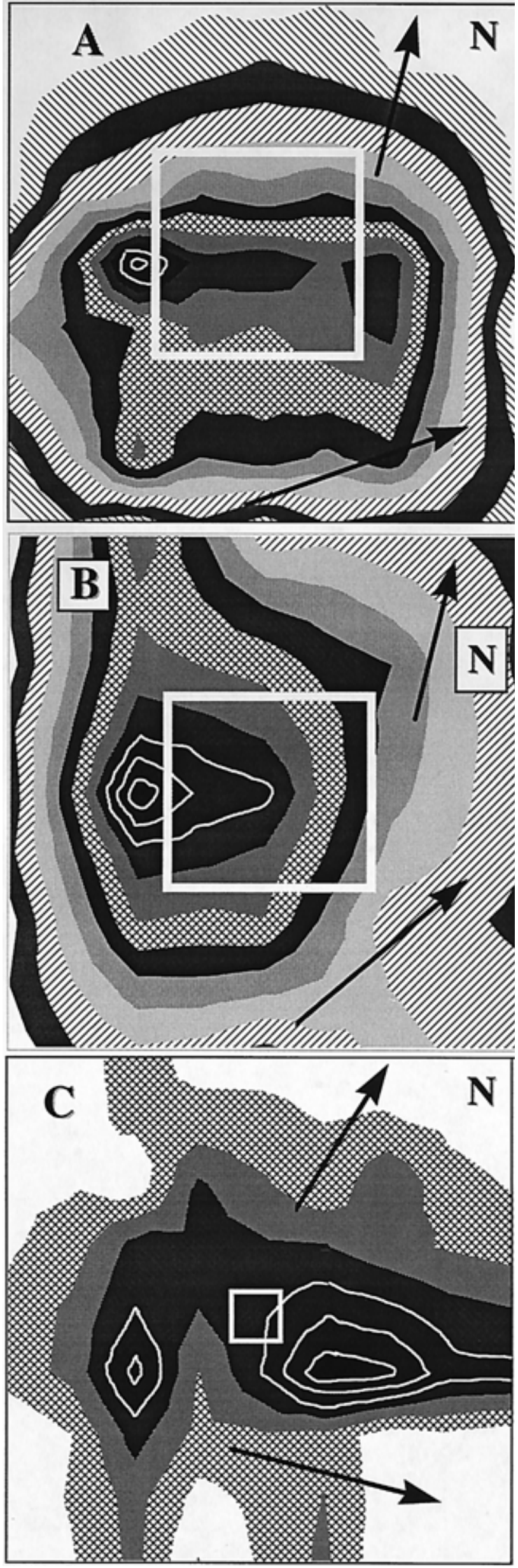

Data were linearized by plotting $\ln (y)$ against $x$. Linear regressions were performed to calculate the gradient slope $(d)$, the y-intercept $(c)$, and the coefficient of determination $\left(r^{2}\right)$. The distances at which disease or infection declined to $50 \%\left(\mathrm{D}_{50}\right)$ and $10 \%\left(\mathrm{D}_{90}\right)$ of that observed at the focal center were determined from the estimated slope values with the equation $\mathrm{D}_{50}=-0.693 / d$ and $\mathrm{D}_{90}=$ $-2.302 / d$. Slopes from the upwind and downwind side of each plot were compared with Student's $t$ test of the regression coefficients, using the standard error of the coefficient estimates and the sum of squares (29).

\section{RESULTS}

Ste. Anne, 1992 and 1993. The nightly wind vector (1600 to $0400 \mathrm{~h}$ ) for the first 3 weeks of July in 1992 and 1993 was from the southwest, $\mathrm{S} 44^{\circ} \mathrm{W}$, and $\mathrm{S} 28^{\circ} \mathrm{W}$, respectively. In both years, the highest incidence of diseased spikelets or seed infection was 0.5 $\mathrm{m}$ from the upwind edge of the inoculated area (Figs. 1A and B and 2), in a direction of $S 65^{\circ} \mathrm{W}$ from the center of the inoculated area. The disease gradients for both years were similar, with a significantly steeper gradient on the upwind side compared with the downwind side of the inoculum area (Table 1). A 50\% decline in visible spikelet infection occurred within 1.6 to $2 \mathrm{~m}$ upwind and within 2.7 to $4.9 \mathrm{~m}$ downwind from disease foci. In 1993, the shape of the contour plots of seed infection and spikelet infection were similar (Figs. 1B and 2). Maximum incidence of seed infec-

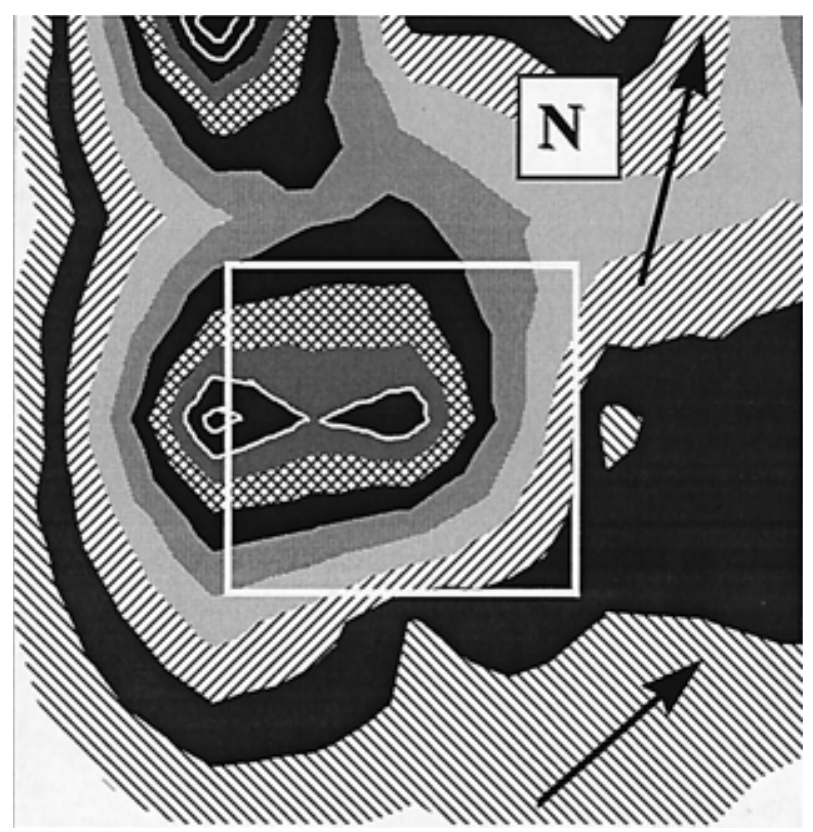

Fig. 2. Isopath contour map of incidence of seed infection in a wheat plot (cultivar Max) inoculated in the center with Gibberella zeae-colonized corn kernels in Ste. Anne de Bellevue, Quebec, Canada, in 1993. Maximum isopath $=86 \%$, minimum $=8 \%$, and contour interval $=8 \%$. Arrows represent north and average nightly wind vector during 1 to 22 July. Total plot size was $10 \times 10 \mathrm{~m}$ and the inoculated area (outlined in white) was $4 \times 4 \mathrm{~m}$.

Fig. 1. Isopath contour maps of incidence of wheat spikelets with symptoms of head blight in plots of cultivar Max inoculated in the center with Gibberella zeae-colonized corn kernels. A, Ste. Anne de Bellevue, Quebec, Canada, in 1992 . Maximum isopath $=12.5 \%$, minimum $=0.21 \%$, and contour interval $=1.0 \%$. B, Ste. Anne de Bellevue in 1993. Maximum isopath $=40.8 \%$, minimum $=1.2 \%$, and contour interval $=3.5 \%$. C, Ottawa, Ontario, Canada, in 1993. Maximum isopath $=76 \%$, minimum $=9.6 \%$, and contour interval $=$ $1 \%$. Each plot was $10 \times 10 \mathrm{~m}$ and the inoculated area (outlined in white) was $4 \times 4 \mathrm{~m}$ in Ste. Anne and $1 \times 1 \mathrm{~m}$ in Ottawa. Arrows indicate north and the average nightly wind vector during 1 to 22 July. 
tion was $86 \%$, but the maximum percent spikelets with symptoms was only $41 \%$. Another focus of spikelet and seed infection developed along one edge of the plots in 1993 (Figs. 1B and 2).

Ottawa, 1993. The patterns of spikelet (Fig. 1C) and seed (Fig. 3A) infection were similar in the plot inoculated with colonized corn kernels. Maximum incidence of disease on spikelets was $76 \%$, and maximum incidence of seed infection was $63 \%$. The highest peak of seed infection was displaced $2.7 \mathrm{~m}$ away from the edge of the inoculated area, in a direction of $\mathrm{S} 20^{\circ} \mathrm{W}$. A second, smaller focus was observed downwind $\left(\mathrm{N} 71^{\circ} \mathrm{E}\right)$ of the inoculum source. Gradients of seed infection were significantly steeper upwind of the inoculum compared with downwind (Table 1).

The focus of infection in the plot inoculated with macroconidia sprayed on heads (Fig. 3C) was more symmetrical than the focus resulting from ascospore infection (Fig. 3A). The infection focus was displaced $1.6 \mathrm{~m}$ from the edge of the inoculated area, in the direction of $\mathrm{S}^{\circ} 1^{\circ} \mathrm{W}$. But the pattern was apparently not influenced by wind direction. The infection gradient was similar on the upwind and downwind sides (Table 1). The infection gradient of the macroconidia-inoculated plots was much steeper than in plots inoculated with ascospore-producing inoculum, and seed infection declined to $50 \%$ within about $1 \mathrm{~m}$.

In the noninoculated plot, seed infection showed an aggregated distribution, with scattered small foci (Fig. 3B). The highest incidence of seed infection (48\%) was found in samples near the border of the ascospore-inoculated plot. The maximum incidence of seed infection at the peaks of the other smaller foci was $27 \%$. The slopes of the infection gradients from these foci were steeper than those observed in plots inoculated with macroconidia or ascospores (Table 1). This indicates only a few plants were diseased in these foci.

Ottawa, 1994. In the two $50 \times 50$-m plots located approximately $1 \mathrm{~km}$ apart, the patterns of seed infection were similar (Fig. 4A and B). In both cases, most infected seed were found east of the inoculated area, which corresponded to the wind direction on the nights of 9 and 10 July (from $N 73^{\circ} \mathrm{W}$ ), during which major release events occurred, as detected with the Burkard spore samplers. Many ascospores were also released on the evenings of 7 and 8 July, when the average wind vector was from $S 8^{\circ} \mathrm{E}$. The nightly wind vector averaged over 1 to 31 July was from S29 $9^{\circ}$. At site 1 (Fig. 4B), two foci were observed, one of which was adjacent to the inoculum site. In the second site (Fig. 4A), a focus of infection was detected $7.5 \mathrm{~m}$ downwind of the inoculum site. The slope of the infection gradient was similar for both sites (Table 2), with no significant differences between the upwind and downwind sides. Seed infection declined by $50 \%$ within 3.8 to 6.7 $\mathrm{m}$ of the center of the focus, and declined by $90 \%$ within 12 to 22 $\mathrm{m}$ of the focal center.
In the $25 \times 25-\mathrm{m}$ quadrats of the second site, maximum seed infection ranged from 60 to $86 \%$, and varying patterns of foci displacement from the inoculated areas were observed (Fig. 5A-D). In the two quadrats on the west (upwind) side of the field (Fig. 5A and $\mathrm{C}$ ), the foci and gradients were flatter and displaced somewhat to the downwind side of the plots. On the east (downwind) side of the field (Fig. 5B and D), the infection foci were centered closer to the inoculated area and some infection was present upwind of the inoculum site. In three of the four subplots, the slopes of the infection gradients were significantly steeper on the upwind side of the infection focus (Table 2) compared with the downwind side. Incidence of infection declined by $90 \%$ within 5 to $21 \mathrm{~m}$ of the center of the disease focus.

In the $10 \times 10-\mathrm{m}$ plot at site 2 inoculated with macroconidia, a low level of infection occurred throughout the field, with two small foci of disease (Fig. 6). Maximum incidence of seed infection at the center of these foci was only $14 \%$, and the slope of the infection gradients was the steepest $(d=-0.48)$ of all foci observed in 1994. Infection declined $90 \%$ within approximately $5 \mathrm{~m}$ from the focal center.

\section{DISCUSSION}

Although Fusarium head blight is endemic to humid areas of eastern North America, little work has been done on the epidemiology of the sexual state, G. zeae. This may be because of the sporadic nature of disease epidemics (21). Our technique of creating artificial epidemics with ascospores arising from perithecia on colonized corn overcame this obstacle. In addition, the use of a strain with a morphological marker (yellow-colored colony reverse) has enabled us to quantify seed infection and to differentiate the test strain from other strains of $F$. graminearum and from other Fusarium species, such as $F$. avenaceum, $F$. poae, and $F$. sporotrichioides, commonly inhabiting wheat seed in eastern Canada $(10,19)$.

In our inoculated plots, the incidence of infected seed may be higher than that found in natural plots. Martin et al. (19) found 9 to $18 \%$ of wheat seed infected with $F$. graminearum in naturally infected plots in Prince Edward Island and Nova Scotia. Seed infection also may be a more accurate assessment of inoculum dispersal than incidence of disease on spikelets. Spikelet incidence can be assessed accurately only for a short period of time before natural senescence of the heads. We found that seed infection was usually higher than disease severity, suggesting that symptomless infections may be common. Symptom expression also may be affected by the physiological age at which infection occurs and symptoms on spikelets may not be expressed from late infections. Despite these differences, gradients and contour maps

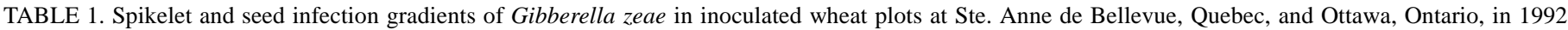
and 1993

\begin{tabular}{|c|c|c|c|c|c|c|c|c|}
\hline \multirow[b]{2}{*}{ Site $^{\mathrm{a}}$ and inoculum ${ }^{\mathrm{b}}$} & \multicolumn{4}{|c|}{ Upwind of inoculum source } & \multicolumn{4}{|c|}{ Downwind of inoculum source } \\
\hline & $\begin{array}{c}\mathrm{y} \text {-intercept }(c)^{\mathrm{c}} \\
(\%)\end{array}$ & $\begin{array}{l}\text { slope }(d)^{\mathrm{c}, \mathrm{d}} \\
\left(\mathrm{m}^{-1}\right)\end{array}$ & $\begin{array}{l}\mathrm{D}_{50}{ }^{\mathrm{e}} \\
(\mathrm{m})\end{array}$ & $\begin{array}{l}\mathrm{D}_{90} \mathrm{f} \\
(\mathrm{m})\end{array}$ & $\begin{array}{c}\mathrm{y} \text {-intercept }(c) \\
(\%)\end{array}$ & $\begin{array}{l}\text { slope }(d) \\
\quad\left(\mathrm{m}^{-1}\right)\end{array}$ & $\begin{array}{l}\mathrm{D}_{50} \\
(\mathrm{~m})\end{array}$ & $\begin{array}{l}\mathrm{D}_{90} \\
(\mathrm{~m})\end{array}$ \\
\hline Ste. Anne 1992 (1A) & 11.7 & $-0.34^{*}$ & 2.0 & $\ldots{ }^{\mathrm{g}}$ & 12.7 & -0.25 & 2.7 & $\ldots$ \\
\hline Ste. Anne 1993 (1B) & 42.9 & $-0.43^{*}$ & 1.6 & $\ldots$ & 41.3 & -0.14 & 4.9 & $\ldots$ \\
\hline Ottawa 1993 ascospore (3A) & 61.9 & $-0.33 *$ & 2.1 & $\ldots$ & 61.1 & -0.13 & 5.4 & $\ldots$ \\
\hline Ottawa 1993 macroconidia (3C) & 52.8 & -0.79 & 0.9 & $\ldots$ & 55.3 & -0.70 & 1.1 & $\ldots$ \\
\hline Ottawa 1993 noninoculated (3B) & 31.5 & -1.08 & 0.6 & 2.1 & 33.0 & -1.94 & 0.3 & 1.2 \\
\hline
\end{tabular}

a All plots were $10 \times 10 \mathrm{~m}$.

${ }^{\mathrm{b}}$ Contour map figure corresponding to gradient is in parentheses.

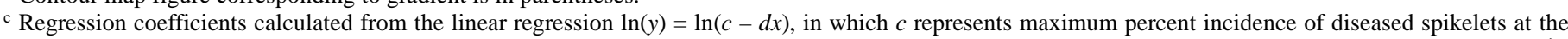
Ste. Anne site or maximum percent incidence of seed infection at the Ottawa site at $x=0 ; x=$ distance from focal center $(\mathrm{m})$ and $d=$ slope of gradient $\left(\mathrm{m}^{-1}\right)$. Coefficient of determination for all regressions $>0.85$, and all regressions were significant at $P<0.05$.

d Slopes marked * were significantly steeper on upwind side than downwind side, based on Student's $t$ test, $P \leq 0.05$.

e The distance at which disease or infection declined to $50 \%$ of that observed at the focal center.

$\mathrm{f}$ The distance at which disease or infection declined to $10 \%$ of that observed at the focal center.

$\mathrm{g}$ Distances could not be extrapolated beyond the size of the field. 

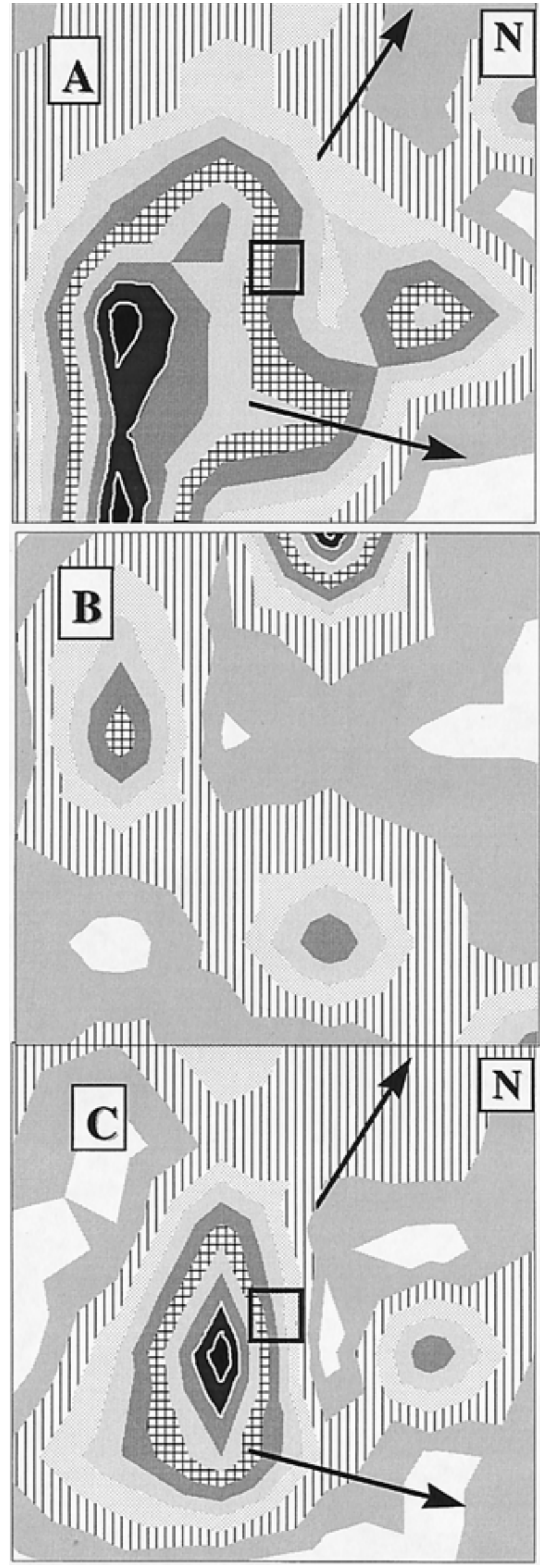
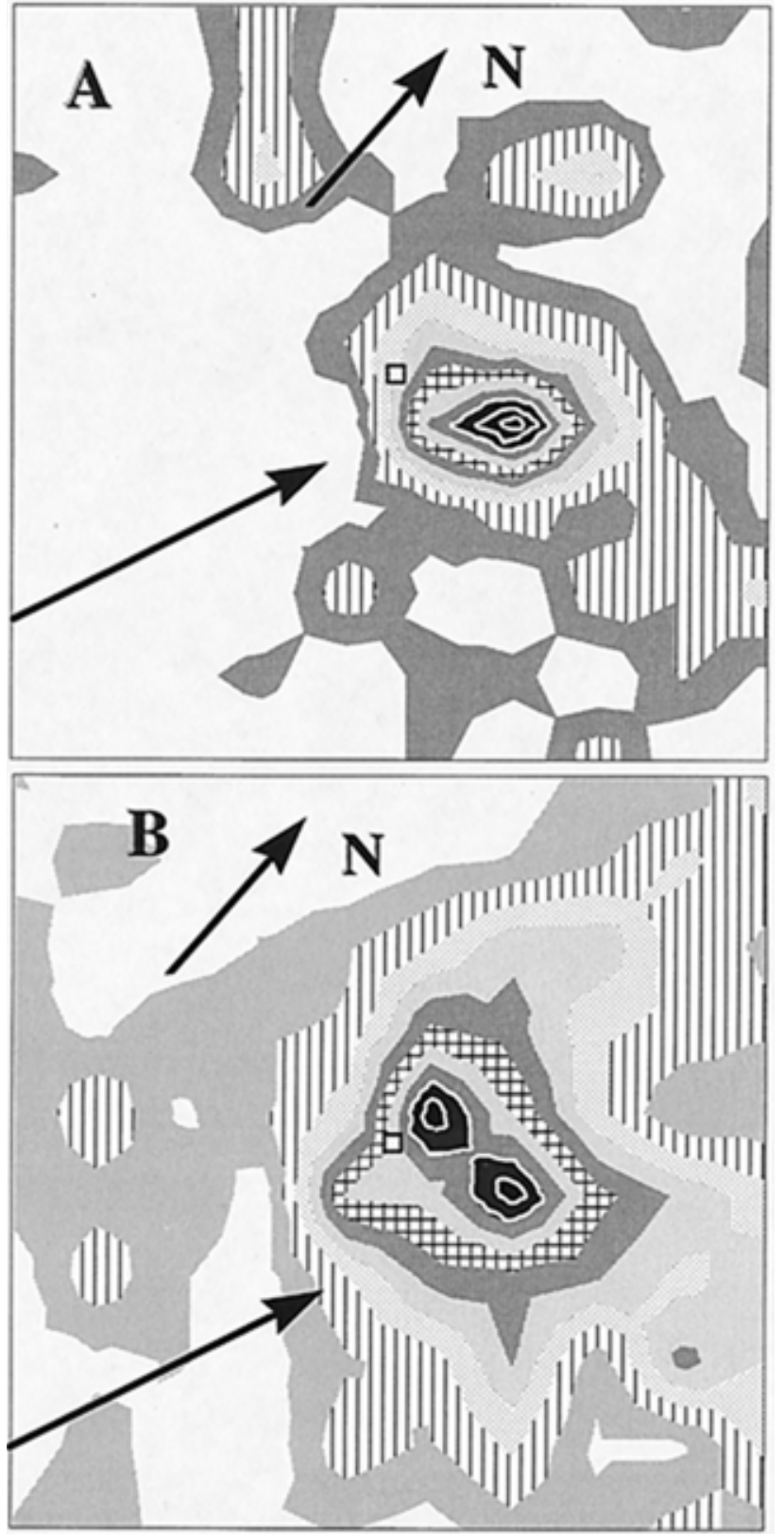

Fig. 4. Isopath contour maps of incidence of seed infection in wheat plots (cultivar Roblin) inoculated in the center with Gibberella zeae-colonized corn kernels in Ottawa, Ontario, Canada, in 1994. A, Site 2, maximum isopath $=34 \%$, minimum $=0 \%$, and contour interval $=3 \%$. B, Site 1 , maximum isopath $=80 \%$, minimum $=0 \%$, and contour interval $=7.5 \%$. Arrows represent north and average nightly wind vectors during 1 to 31 July. Each plot was $50 \times 50 \mathrm{~m}$ and the inoculated area (white square) was $1 \times 1 \mathrm{~m}$.

Fig. 3. Isopath contour maps of incidence of seed infection in wheat plots (cultivar Max) inoculated in the center with A, Gibberella zeae-colonized corn kernels; B, nothing; or C, macroconidia in Ottawa, Ontario, Canada, in 1993. A, Maximum isopath $=64 \%$, minimum $=0 \%$, and contour interval $=$ $6 \%$. B, Maximum isopath $=52 \%$, minimum $=2 \%$, and contour interval $=$ $5 \%$. C, Maximum isopath $=54 \%$, minimum $=0 \%$, and contour interval $=$ $5 \%$. Each plot was $10 \times 10 \mathrm{~m}$ and the inoculated area (outlined in black) was $1 \times 1 \mathrm{~m}$. Plots were misted during anthesis. Arrows represent north and average nightly wind vector during 1 to 22 July. 


\begin{tabular}{|c|c|c|c|c|c|c|c|c|}
\hline \multirow[b]{2}{*}{$\underline{\text { Site and plot size }}{ }^{\mathrm{a}}$} & \multicolumn{4}{|c|}{ Upwind of the inoculum source } & \multicolumn{4}{|c|}{ Downwind of the inoculum source } \\
\hline & $\begin{array}{c}\mathrm{y} \text {-intercept }(c)^{\mathrm{b}} \\
(\% \text { seed infection })\end{array}$ & $\begin{array}{c}\text { slope }(d)^{\mathrm{b}, \mathrm{c}} \\
\left(\mathrm{m}^{-1}\right)\end{array}$ & $\begin{array}{l}\mathrm{D}_{50}^{\mathrm{d}} \\
(\mathrm{m})\end{array}$ & $\begin{array}{l}\mathrm{D}_{90} \mathrm{e} \\
(\mathrm{m})\end{array}$ & $\begin{array}{c}\mathrm{y} \text {-intercept }(c) \\
(\% \text { seed infection })\end{array}$ & $\begin{array}{c}\text { slope }(d) \\
\left(\mathrm{m}^{-1}\right)\end{array}$ & $\begin{array}{l}\mathrm{D}_{50} \\
(\mathrm{~m})\end{array}$ & $\begin{array}{l}\mathrm{D}_{90} \\
(\mathrm{~m})\end{array}$ \\
\hline Site $1(4 B) 50 \times 50 \mathrm{~m}$ & 80.8 & -0.11 & 6.0 & 19.8 & 80.3 & -0.10 & 6.7 & 22.3 \\
\hline Site $2(4 \mathrm{~A}) 50 \times 50 \mathrm{~m}$ & 40.2 & -0.18 & 3.8 & 12.7 & 34.1 & -0.19 & 3.7 & 12.2 \\
\hline $\mathrm{SE} 1 / 4(5 \mathrm{D}) 25 \times 25 \mathrm{~m}$ & 65.2 & -0.26 & 2.7 & 8.9 & 73.5 & -0.44 & 1.6 & 5.2 \\
\hline $\mathrm{SW} 1 / 4(5 \mathrm{C}) 25 \times 25 \mathrm{~m}$ & 89.7 & $-0.37 *$ & 1.9 & 6.2 & 87.3 & -0.16 & 4.3 & 14.4 \\
\hline $\mathrm{NE} 1 / 4(5 \mathrm{~B}) 25 \times 25 \mathrm{~m}$ & 63.7 & $-0.33^{*}$ & 2.1 & 7.0 & 61.1 & -0.16 & 4.4 & 14.6 \\
\hline NW $1 / 4(5 \mathrm{~A}) 25 \times 25 \mathrm{~m}$ & 61.9 & $-0.27 *$ & 2.5 & 8.4 & 60.8 & -0.11 & 6.3 & 20.9 \\
\hline Macroconidia (6) $10 \times 10 \mathrm{~m}$ & 14.7 & -0.48 & 1.4 & 4.8 & 13.6 & -0.48 & 1.4 & 4.8 \\
\hline
\end{tabular}

a Contour map figure corresponding to gradient is in parentheses.

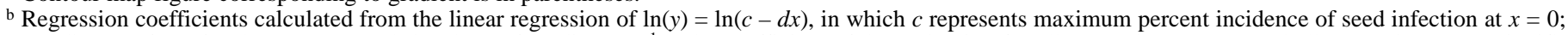
$x=$ distance from focal center $(\mathrm{m})$ and $d=$ slope of gradient $\left(\mathrm{m}^{-1}\right)$. The coefficient of determination for all regressions $>0.85$, and all regressions were significant $P<0.05$.

c Slopes marked * are significantly steeper on upwind side than downwind side, based on Student's $t$ test, $P \leq 0.05$.

$\mathrm{d}$ The distance at which disease or infection declined to $50 \%$ of that observed at the focal center.

e The distance at which disease or infection declined to $10 \%$ of that observed at the focal center.
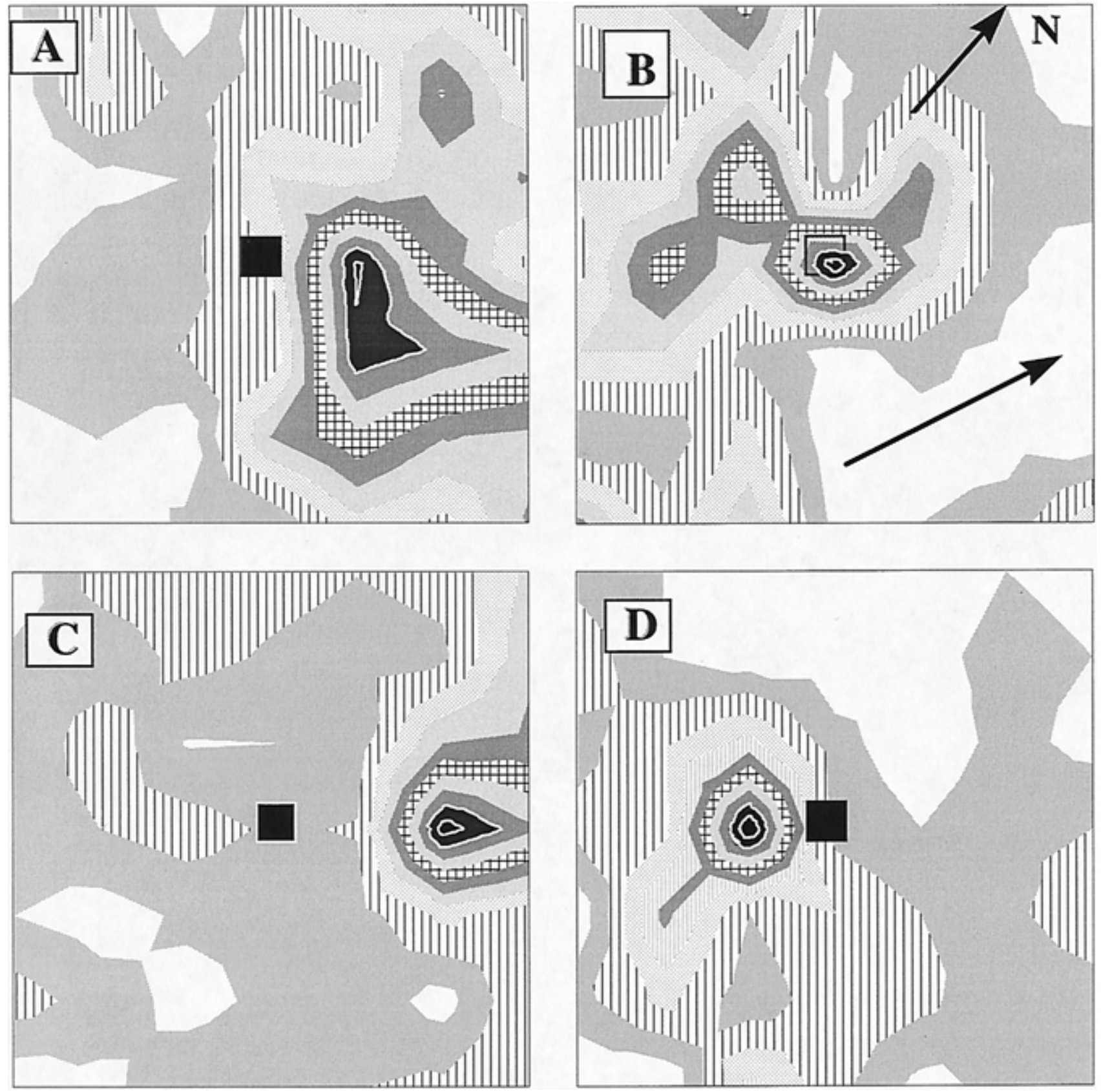

Fig. 5. Isopath contour maps of incidence of seed infection in wheat plots (cultivar Roblin) inoculated in the center with Gibberella zeae-colonized corn kernels in Ottawa, Ontario, Canada, site 2, in 1994. A, Northwest quadrant, maximum isopath $=60 \%$, minimum $=0 \%$, and contour interval $=6 \%$. B, Northeast quadrant, maximum isopath $=64 \%$, minimum $=0 \%$, and contour interval $=6 \%$. C, Southwest quadrant, maximum isopath $=84 \%$, minimum $=2 \%$, and contour interval $=8 \%$. D, Southeast quadrant, maximum isopath $=66 \%$, minimum $=0 \%$, and contour interval $=6 \%$. Each quadrant was $25 \times 25 \mathrm{~m}$ and the inoculated area (black square) was $1 \times 1 \mathrm{~m}$. Arrows represent north and average nightly wind vectors for 1 to 31 July. 
of spikelet incidence and incidence of seed infection were similar, when measured at two locations in 1993.

To our knowledge, this is the first comprehensive study of dispersal and disease gradients of G. zeae in wheat. This also is one of the few studies that have examined dispersal in two dimensions using grid sampling. Most dispersal studies have measured disease using line transects from the source, either in four directions $(1,22)$ or eight directions $(9)$. By sampling in two dimensions, a more complete picture of infection or disease dispersal can be drawn, since information from adjacent points can be used in the model to provide the best isopath fit (26). Several conclusions can be drawn from our data. The patterns of dispersal from small area sources of inoculum showed discrete foci with fairly sharp gradients, suggesting a primary gradient resulting from a spore release event over a short period of time. Had secondary inoculum been produced, the gradients probably would have been flattened (7).

The value $d$ from the exponential model has the units of $\mathrm{m}^{-1}$, and is dependent on the units of $x$. However, it is considered to be independent of the value of $y$, or the strength of the inoculum or disease at the source, $x=0$ (20). Therefore, it provides a useful tool for comparing the gradients from different studies that have also used the exponential model. In our study, we measured gradients from inoculated sources ranging from -0.11 to $-0.79 \mathrm{~m}^{-1}$. Fitt et al. (12), using data from Keitt et al. (17), calculated a value of $d$ $=-0.015$ for Venturia inaequalis in apple orchards. Gradients of disease severity of soybean stem canker, a monocyclic disease caused by Diaporthe phaseolorum var. caulivora, ranged from -0.25 to $-1.5 \mathrm{~m}^{-1}$ (9). This fungus produces both conidia and ascospores, but is thought to be mostly splash-dispersed.

In our work, the slopes of the gradients produced by ascospores were similar to those caused by other airborne spores, such as rusts, if only primary infection was considered. For example, Mundt (22) measured disease gradients of Puccinia recondita in a wheat field ranging from -0.07 to $-0.28 \mathrm{~m}^{-1}$ from a $3.66 \times 3.66-\mathrm{m}$ area of inoculum. Aylor (3), using the same host-pathogen system, determined gradients of -0.6 to $-1.42 \mathrm{~m}^{-1}$, using trap plants exposed for 2 to $3 \mathrm{~h}$ at various distances from an inoculum source. McCartney and Bainbridge (20) used droplets of $20-\mu \mathrm{m}$ diameter to simulate spores released in the mid-canopy of full height barley

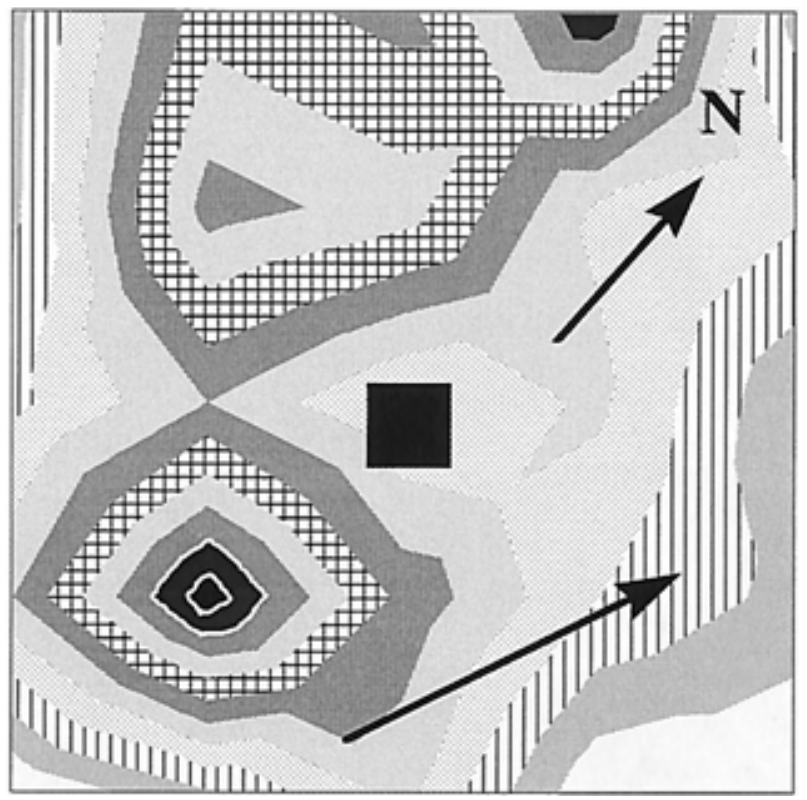

Fig. 6. Isopath contour map of map of incidence of seed infection in wheat plots (cultivar Roblin) inoculated in the center with macroconidia of Gibberella zeae in Ottawa, Ontario, Canada, in 1994. Maximum isopath $=13 \%$, minimum $=0 \%$, and contour interval $=1.2 \%$. The plot was $10 \times 10 \mathrm{~m}$ and the inoculated area (black square) was $1 \times 1 \mathrm{~m}$. Arrows represent north and average nightly wind vectors during 1 to 31 July. and detected a gradient of $-1.6 \mathrm{~m}^{-1}$. However, the gradient for powdery mildew in a peach orchard was much shallower, ranging from -0.04 to $-0.08 \mathrm{~m}^{-1}$ (16).

In contrast, spore dispersal gradients of splashborne fungi tend to be much steeper than those of airborne spores. For example, the value of $d$ for splashborne spores of Septoria nodorum in wheat was estimated to be $-4.68 \mathrm{~m}^{-1}(6)$. Using a rain-wind tunnel, Yang and TeBeest (34) simulated the splash dispersal of Colletotrichum gloeosporioides in rice and found spore gradients of -0.8 to -1.63 $\mathrm{m}^{-1}$. Spore dispersal gradients of Pseudocercosporella herpotrichoides in wheat ranged from -4 to $-11 \mathrm{~m}^{-1}$ (12). The number of spores of Colletotrichum acutatum splashed from infected fruit on straw under a simulated rain were almost reduced to zero $1.2 \mathrm{~m}$ from the source (33). The lack of such steep gradients in our experiments may indicate that airborne ascospores were more important in establishing the foci than splashborne macroconidia. In all years, we observed sporodochia and macroconidia on the inoculated corn kernels before and during perithecium formation. However, splash dispersal of macroconidia onto the heads may occur only during intense rain periods before the canopy is closed (14); closure of the canopy would reduce the impact velocity of the raindrops. Jenkinson and Parry (14), using simulated 5-mm drops, showed that conidia of $F$. culmorum could be splash-dispersed as high as 60 and $100 \mathrm{~cm}$ from the source.

The patterns of infections within an area source of inoculum were not uniformly symmetrical. In 1992 and 1993 at Ste. Anne, the centers of the foci were on the upwind side of the $4 \times 4-\mathrm{m}$ inoculation plots, and yet there was a dispersal of inoculum in the downwind direction. This may have been due to changing wind direction or turbulence at the edge of the field, since the edge of the inoculum area was only $3 \mathrm{~m}$ from the edge of the field. This trend was not evident in the 1994 experiments with larger fields and smaller inoculum source areas.

Wind determined, in part, the location of the infection relative to the inoculum source. In both 1993 and 1994, the direction of the spread of disease from the inoculum source was correlated with the nightly wind vectors during the first 3 weeks of July, the same time during which ascospore release events occurred (26). In 1994, many of the focal centers of infection were displaced from the inoculum source by as much as $7 \mathrm{~m}$ downwind. This is probably due to the movement of the ascospore cloud from the inoculum source, which is dependent on the wind velocity and direction at the time of release. However, the location of the inoculum in the field relative to the field edge also may determine the position of the focal centers. Crop canopies modify airflow by creating friction and turbulence. Hirst and Stedman (13) showed that the canopy of wheat influenced the efficiency of spore deposition and the vertical profile of spore numbers, as measured by using sugar beet pollen. This may explain the location effects we observed.

The infection gradient, which reflects a gradient of spore deposition, was usually steeper on the upwind side of the focus compared with that on the downwind side. This is consistent with other observations with airborne spores $(5,7,9,12)$. Damicone et al. (9) also found a greater downwind dispersal of splashborne spores. In our 1994 study, the gradients on the downwind side of the main plot extended 4 to $22 \mathrm{~m}$ downwind from the focal center (Table 2). This type of information may be useful in estimating the spread of ascospore inoculum from heavily infested fields. This does not, however, preclude the possibility of other spore clouds breaking away from the main cloud and depositing ascospores further away. We saw some evidence of smaller, secondary foci that developed some distance from the primary foci (Figs. 1C, 3A and $\mathrm{B}$, and 4A). These smaller, secondary foci had a much steeper gradient than the primary foci. With our limited field size, we could not assess possible long distance dispersal of spore clouds, and it would take a large amount of sampling to detect the small foci that would result. 
The gradient of infection in the misted ascospore-inoculated plot (Figs. 1C and 3A) was flatter than that in the nonirrigated plots (Figs. 1B, 2, 4, and 5). In central Washington state, a semiarid area, $F$. graminearum was more prevalent in overhead-irrigated wheat than in dryland wheat (31). The diffuse infection patterns may have resulted from more numerous spore release events than that in nonirrigated plots, because of the favorable conditions for perithecial formation and ascospore maturity. Perithecial formation and maturity are correlated with the moisture levels of the substrate (T. C. Paulitz and W. G. D. Fernando, unpublished data). This diffuse pattern also could be due to the conducive conditions for ascospore infection once the spores landed, so more of the spore release events resulted in successful infections. It is unlikely that the spread was due to secondary infections, since the macroconidia-inoculated plot at the same site showed a discrete focus with a steep gradient. This experiment also demonstrated that there was limited movement of spores from macroconidia-inoculated heads, even under ideal misted conditions. Although sporodochia were on many infected heads in the field, these macroconidia did not appear to have caused secondary infections. The period of susceptibility of the wheat head may be limited, so that the plants were resistant by the time secondary sporulation occurred. Previous work has shown that anthesis is the most susceptible period $(2,30)$. The heads of secondary tillers that formed later were not sampled in this study and may be subject to secondary infection if they flowered after sporodochia were formed on the primary heads.

Analysis of infection gradients provides useful information for the control of Fusarium head blight of wheat. For example, minimum isolation distances to separate susceptible crops in crop rotations can be calculated using appropriate spatial modeling. The resistances of cultivars can be evaluated under field conditions by measuring disease gradients. Work is also needed to establish the spatial patterns of this pathogen in naturally infected fields, which would be useful for developing management strategies for head blight.

\section{ACKNOWLEDGMENTS}

We thank J. Brown, K. Fraser, S. Godkin, H. Harper, B. Payne, and F. Sabo at Agriculture and Agri-Food Canada, Ottawa, and J. Owen, Z. Kabir, S. Hussan, Y. Dupeux, K. Belazaire, J. P. Laplante, and M. Bleho of Macdonald Campus of McGill University for technical and field assistance. We also thank $\mathrm{H}$. Cohen-Rimmer for her assistance with the contour maps and C. Mundt for reviewing the manuscript.

\section{LITERATURE CITED}

1. Alderman, S. C., Nutter, F. W., Jr., and Labrinos, J. L. 1989. Spatial and temporal analysis of spread of late leaf spot of peanut. Phytopathology 79:837-844.

2. Andersen, A. L. 1948. The development of Gibberella zeae headblight of wheat. Phytopathology 38:595-611.

3. Aylor, D. E. 1987. Deposition gradients of urediniospores of Puccinia recondita near a source. Phytopathology 77:1442-1448.

4. Bai, G., and Shaner, G. 1994. Scab of wheat: Prospects for control. Plant Dis. 78:760-766

5. Bainbridge, A., and Stedman, O. J. 1979. Dispersal of Erysiphe graminis and Lycopodium clavatum spores near to the source in a barley crop. Ann. Appl. Biol. 91:187-198.

6. Brennan, R. M., Fitt, B. D. L., Taylor, G. S., and Colhoun, J. 1985. Dispersal of Septoria nodorum pycnidiospores by simulated rain and wind. J. Phytopathol. 112:291-297.

7. Cammack, R. H. 1958. Factors affecting infection gradients from a point source of Puccinia polysora in a plot of Zea mays. Ann. Appl. Biol. 46:186-197.

8. Charmley, L. L., Rosenberg, A., and Trenholm, H. L. 1994. Factors responsible for economic losses due to Fusarium mycotoxin contamination of grains, foods, and feedstuffs. Pages 471-486 in: Mycotoxins in Grain: Compounds Other Than Aflatoxins. J. D. Miller and H. L. Trenholm, eds. American Association of Cereal Chemists, St. Paul, MN.

9. Damicone, J. P., Snow, J. P., and Berggren, G. T. 1990. Spatial and temporal spread of soybean stem canker from an inoculum point source. Phytopathology 80:571-578.

10. Fauzi, M. T., and Paulitz, T. C. 1994. The effect of plant growth regulators and nitrogen on Fusarium head blight of the spring wheat cultivar Max. Plant Dis. 78:289-292.

11. Fernando, W. G. D., Paulitz, T. C., Seaman, W. L., Miller, J. D., and Dutilleul, P. 1996. Spore release and infection gradients of Gibberella zeae from a point source inoculum in a wheat field. (Abstr.) Can. J. Plant Pathol. 18:89.

12. Fitt, B. D. L., Gregory, P. H., Todd, A. D., McCartney, H. A., and Macdonald, O. C. 1987. Spore dispersal and plant disease gradients: A comparison between two empirical models. J. Phytopathol. 118:227-242.

13. Hirst, J. M., and Stedman, O. J. 1971. Patterns of spore dispersal in crops. Pages 229-237 in: Ecology of Leaf Surface Micro-Organisms. T. F. Preece and C. H. Dickinson, eds. Academic Press, London.

14. Jenkinson, P., and Parry, D. W. 1994. Splash dispersal of conidia of Fusarium culmorum and Fusarium avenaceum. Mycol. Res. 98:506-510.

15. Jenkinson, P., and Parry, D. W. 1994. Isolation of Fusarium species from common broad-leaved weeds and their pathogenicity to winter wheat. Mycol. Res. 98:776-780.

16. Kable, P. F., Fried, P. M., and MacKenzie, D. R. 1980. The spread of a powdery mildew of peach. Phytopathology 70:601-604.

17. Keitt, G. W., Clayton, C. N., and Langford, M. H. 1941. Experiments with eradicant fungicides for combating apple scab. Phytopathology 31:296-322.

18. Kiyosawa, S., and Shiyomi, M. 1972. A theoretical evaluation of the effect of mixing resistant variety with susceptible variety for controlling plant diseases. Ann. Phytopathol. Soc. Jpn. 38:41-51.

19. Martin, R. A., MacLeod, J. A., and Caldwell, C. 1991. Influences of production inputs on incidence of infection by Fusarium species on cereal seed. Plant Dis. 75:784-788.

20. McCartney, H. A., and Bainbridge, A. 1984. Deposition gradients near to a point source in a barley crop. J. Phytopathol. 109:219-236.

21. Miller, J. D. 1994. Epidemiology of Fusarium ear rot diseases of cereals. Pages 19-36 in: Mycotoxins in Grain: Compounds Other Than Aflatoxins. J. D. Miller and H. L. Trenholm, eds. American Association of Cereal Chemists, St. Paul, MN.

22. Mundt, C. C. 1989. Use of modified Gregory model to describe primary disease gradients of wheat leaf rust produced from area sources of inoculum. Phytopathology 79:241-246.

23. Nash, S., and Snyder, W. C. 1962. Quantitative estimations by plate counts of propagules of the bean root rot Fusarium in field soils. Phytopathology 52:567-572.

24. Nirenberg, H. I. 1981. A simplified method for identifying Fusarium spp. occurring on wheat. Can. J. Bot. 59:1599-1609.

25. Parry, D. W., Jenkinson, P., and McLeod, L. 1995. Fusarium ear blight (scab) in small grain cereals-A review. Plant Pathol. 44:207-236.

26. Paulitz, T. C. 1996. Diurnal release of ascospores by Gibberella zeae in inoculated wheat plots. Plant Dis. 80:674-678.

27. Paulitz, T. C., Seaman, W. L., and Dutilleul, P. 1994. Disease and infection gradients of Fusarium head blight (Gibberella zeae) in wheat. (Abstr.) Phytopathology 84:1142.

28. Stack, R. 1994. Understanding scab epidemics. Pages 1-2 in: Proceedings of the Regional Scab Forum and Research Conference, 1994. North Central Regional Committee 184, Fargo, ND.

29. Steel, R. G. D., and Torrie, J. H. 1960. Principles and Procedures of Statistics. McGraw-Hill Book Co., New York.

30. Strange, R. N., and Smith, H. 1971. A fungal growth stimulant in anthers which predisposes wheat to attack by Fusarium graminearum. Physiol. Plant Pathol. 1:141-150.

31. Strausbaugh, C. A., and Maloy, O. C. 1986. Fusarium scab of irrigated wheat in central Washington. Plant Dis. 70:1104-1106.

32. Sutton, J. C. 1982. Epidemiology of wheat head blight and maize ear rot caused by Fusarium graminearum. Can. J. Plant Pathol. 4:195-209.

33. Yang, X., Madden, L. V., Wilson, L. L., and Ellis, M. A. 1990. Effect of surface topography and rain intensity on splash dispersal of Colletotrichum acutatum. Phytopathology 80:1115-1120.

34. Yang, X. B., and TeBeest, D. O. 1992. Rain dispersal of Colletotrichum gloeosporioides in simulated rice field conditions. Phytopathology 82:1219-1222. 